\title{
GED - TOOLKIT: OPEN GEOSPATIAL DATA AND TOOLS TO SUPPORT GENERATIVE ECONOMY PROCESSES IN LOCAL COMMUNITIES
}

\author{
Matteo Clementi ${ }^{* 1}$, Erpinio Labrozzi ${ }^{1}$ \\ 1 DAStU, Department of Architecture and Urban Studies, Politecnico di Milano - Via Bonardi 3, 20133, Italy \\ * Corresponding author: Matteo Clementi, matteo.clementi@polimi.it
}

KEY WORDS: Generative Economy, Sustainable Environmental Design, Territorial LCA, FOSS GIS, Impact Geographies, Resources Geographies, Renewable Resources.

\begin{abstract}
:
How can FOSS GIS support generative economy processes in small settled communities?

The paper answers this question by proposing a toolbox made up of specific open geospatial data that can be processed through FOSS GIS. These data consist of specific maps, accompanied by numerical values.

The information collected is intended to lay the foundations for an open-access manual of procedures to support the creation of an open database. This manual, currently under development, is created within a research funded by the Department of Architecture and Urban Studies of the Politecnico di Milano and is an integral part of an experimental game aimed at supporting students in the development of local self-sustainability scenarios.

The manual is called the GED Toolkit. The acronym GED stands for Generative Environmental Design, with this term we refer to an approach to the design of the anthropized environment oriented towards the development of generative economies.

The paper presents good practices, measuring their consistency with Generative Economy Principles through resource and impacts mapping. These are useful in the first place to understand the systemic features of the practice itself and the relationship with the territory that hosts it, and secondly to verify the possible transferability to other contexts.
\end{abstract}

\section{INTRODUCTORY NOTES}

\subsection{United Nation SDGs}

The current focus on sustainable development, led to the development of shared initiatives all over the world summarized by the United Nations Sustainable Development Goals (SDG) (https://sdgs.un.org/goals). Despite the apparent different areas of reference, pursuing one of these goals involves systemic effects, as they affect each other to a lesser or greater extent.

The systemic nature of SDGs is more evident in some of them such as SDG 11, "Sustainable Cities and Communities" (Make cities and human settlements inclusive, safe, resilient and sustainable), or SDG 7 "Affordable and Clean Energy" (Ensure access to affordable, reliable, sustainable and modern energy for all), SDG 8 "Decent Work and Economic Growth" (Promote sustained, inclusive and sustainable economic growth, full and productive employment and decent work for all) and SDG 12 "Responsible Consumption and Production" (Ensure sustainable consumption and production patterns).

The term "sustainable" always appears in the full wording that describes these SDGs, and is placed side by side with the term "community".

It is fundamental to pay attention to those categories of consumption that most affect the environmental sustainability of a community, namely housing, food and transport, followed by services (Baccini, Brunner, 2012). Furthermore, acknowledging the term sustainability as intended by Herman Daly (Daly, 1990), in order to verify the principles of sustainability, it is essential to be aware of the flows activated by these consumption activities and the relationships between these and the ecosystems involved both at the global and local scale.

\subsection{Generative Economy and systemic approach}

The pursuit of the SDGs and in particular the Goal 11 requires the development of effective solutions and a systemic framework involving different disciplinary areas. The specific field of Generative Economy (GE) offers interesting ideas and principles to keep the systemic vision active in the development of project proposals. Generative Economy is defined by Marjorie Kelly (Kelly, 2012), as $<<$ A corner of the economy (hopefully someday much more) that's not designed for the extraction of maximum financial wealth, its purpose is to create the conditions for life $>>$.

A natural ecosystem organizes itself, if undisturbed, to maximize the internal flow of usable solar energy (Odum, 1996) and tend to evolve, if undisturbed, in the direction of maximum eco-efficiency, trying to extract as much work as possible from the same amount of natural capital used (Daly, Farley, 2004). In that sense, the relationship between the creation of vital conditions, sustainability principles and the maximization of the eco-efficiency of a system are evident. Therefore, considering that the assumptions underlying an evolving ecosystem and a sustainable community are the same, the term sustainability is closely linked to the maintenance and increase of vital conditions. In this regard, a recent publication in the field of generative economy, "The Making of a Democratic Economy" (Kelly, 
Ted, 2019) proposes 7 general principles, presented in paragraph 2.2, useful to identify a process of Generative Economy, and consequently to develop design scenarios that The main goal of this paper is to link these principles with open source and open data tools to create an opportunity for debate and comparison on open source tools to support the development of project scenarios oriented to the activation of GE processes.

The verification of these GE principles implies particular attention to the quantitative aspects associated with the dynamics that put in relation settled communities and territories. Furthermore, the elaboration of improvement scenarios aimed at pursuing these principles implies the quantitative assessment of the current state and the state of the project. This activity requires the use of tools capable of quantifying the impacts but also of developing improvement scenarios while maintaining control over the systemic relationships activated by the lifestyle of a community settled in the area.

\subsection{Tools and open data}

This systemic vision can be managed by tools such as the Territorial Life Cycle Assessment (TLCA) (Loiseau et al., 2018) which sees in the analysis of the life cycle of a product or service an effective tool to take into account the systemic relationships between activities and the territory that hosts them.

Unlike the conventional LCA which allows a quantitative assessment of the dynamics associated with a supply chain of a product or service, the TLCA associates these quantities with the georeferencing of the dynamics involved, enhancing a strong design value oriented towards maximizing the ecoefficiency of the system. In particular, the relationships between anthropic activities and production activities based on territorial regenerative cycles are taken into consideration.

As already reported in previous papers (Loiseau et al., 2018), being TLCA a recently developed method, this new approach to life cycle assessment requires new experimental tools to support the analysis and development of improvement scenarios based on GIS in order to associate the amount of energy and matter involved in the process.

\subsection{FOSS GIS and Territorial LCA}

The application of TLCA requires tools that are useful for a systemic analysis of these activities, that is to say, which allow to put in relation activities, territory and the different disciplinary areas between them. The current development of open source software and open databases offers new possibilities in this direction. In particular, the current state of advancement of open source sw to support life cycle analysis (https://www.openlca.org/), of open source databases to support the compilation of the same sw (https://nexus.openlca.org/), and the current level of development of open source GIS make the current moment in favour for an in-depth study of the potential offered by these tools in the analysis of environmental impacts and the development of improvement scenarios oriented towards sustainable reconnection between economic activities and local natural ones. While, on the one hand, databases and LCA support tools allow to quantify the activities in terms of flows are aware of the systemic relationships between the various actors involved and oriented towards the creation of sustainable communities.

of energy and matter in the main phases of their life cycle and therefore assess their environmental loads, on the other hand, GIS give the possibility to put in relation these dynamics with the specific features of the territory that hosts them. This possibility is very useful for weighting the environmental impacts based on the actual characteristics of the territory they affect (Regionalized LCA) (Rodríguez et al., 2014). They would be all the more useful in the development of improvement scenarios aimed at raising the eco-efficiency of the system, through the use of local renewable sources and the integration of different supply chains present in the same territory. The integrated use of these sws would make it possible to keep on the same georeferenced database information made available by open databases and relating to different areas of investigation.

\section{METHOD}

\subsection{A Generative Environmental Design approach}

The "GED Toolkit" handbook of which this publication aims to illustrate some methodological features, intends to guide the user in the construction of geographies useful for the development of scenarios that respect the GE principles. The term GED is the acronym for Generative Environmental Design and is defined in this paper as an approach to the design of the anthropized environment oriented towards the development of Generative Economies, i.e. based on the generative cycles that constitute the natural (circular) metabolism of the territory.

Therefore, the proposed method maps and quantifies the features of the territory, and understands the dynamics related to the main activities of a specific community through the construction of "geographies". To this end, useful tools to represent this information on the same georeferenced support are offered by the Impact Geographies (IG) and Resource Geographies (RG) (Clementi et al., 2018).

\subsection{The principles of a Generative Economy}

The approach presented by Kelly puts on the same level aspects associated with labour, social inclusion and respect for natural cycles by defining 7 peculiar principles of a Generative Economy:

P1 - "The principles of community.

P2 - The principle of inclusion. Inclusion refers to creating opportunities for those long excluded.

P3 - The principle of place. Building community wealth that stays local.

P4 - The principle of good work. Putting labour before capital. P5 - The principle of democratized ownership. Ownership resides with different publics, which could be the workers, the community, the municipal authority, or where appropriate, investors.

P6 - The principle of sustainability. Protecting the ecosystem as the foundation of life.

P7 - The principle of ethical finance. Investing and lending for people and places. In ethical finance, social and ecological benefit is the aim" (Kelly, Ted, 2019). 
The relationship between economic flows and the territory that hosts them is of fundamental importance in these processes and is highlighted in particular by principles 3 and 7 , namely, the principle of place and the principle of sustainability.

To support the pursuit of these principles, the construction of geographies should on the one hand know and map the salient features of the territory, and on the other understand the dynamics related to the main activities of the settled community. To this end, useful tools to represent this information on the same georeferenced support are offered by the Impact Geographies (IG) and Resource Geographies (RG) (Clementi et al., 2018). The meeting of the seven principles can be measured through meaningful indicators that will vary depending on the specific territory, flow, or system addressed, as presented in Chapter 3 .

\subsection{Impact Geographies and Resources Geographies}

Resources and Impacts Geographies are obtained by collecting on the same territorial support information on local demand of energy and matter and on the renewable energy and matter locally available. Information on Local Demand of Energy and Matter are collected in the form of Impact Geographies, while information on Renewable Energy and Matter are collected as Resources Geographies related to local supply. Both types of maps can be processed using open source gis software currently available such as $\mathrm{r}$ QGIS (www.qgis.org) and GRASS-GIS (https://grass.osgeo.org/).

In particular, the IGs allow a graphic visualization useful to understand the relations with the territory and to relate the energy and matter demand and resources available locally (Fig. 1).

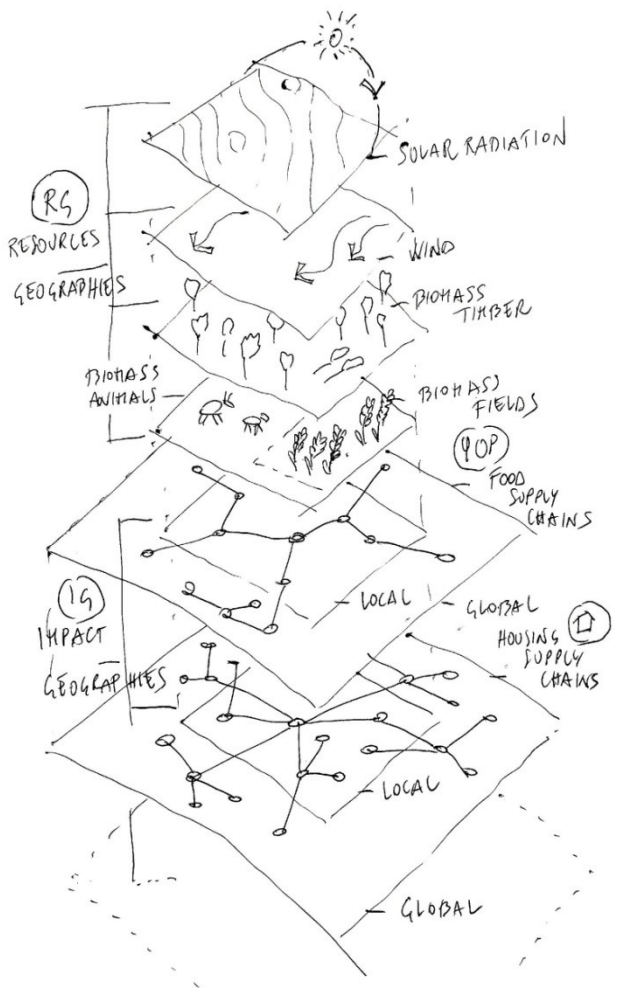

Figure 1. Example image representing Resource geographies (RG) and Impact Geographies (IG) in the same GIS.
"IG are characterized by a common structure consisting of georeferenced vectors representative of the main supply chain phases of a general product. By supply chain we mean the entire life cycle of a material or energy product, from extraction/production, to manufacturing/processing, to consumption, until the end of life and the generation of waste. In particular, the information associated to each supply chain are divided into two distinct layers (shapefile):

- Supply chain nodes, consisting of points associated with the quantities of energy and matter involved in the production/consumption phases (i.e. the set of activities related to the supply chain that take place in the same place).

- The connections between them, consisting of lines connecting the points, associates to vectors information concerning the transport of the material from one node to another (modes, quantities, distances)" (Clementi et al., 2018), and visualizing the flows between points

The procedures presented in the "GED Toolkit" relate these tools to the GE principles and are implemented based on the information that emerges in the application of these tools to real good practices consistent with the GE principles.

\subsection{IG and RG applied to the consumption category of the home}

In order to test the potential use of the tools presented above, it was decided to limit the scope of the investigation to the environmental impacts of the home. The main items that make up the environmental loads of the home are summarized in Figure 2. From the specific point of view of the Life Cycle Analysis applied to the sustainability assessment of a community, they assume a branched graphic depicting the domestic (knowledgeable as a minimum community) material and energy expenditures.

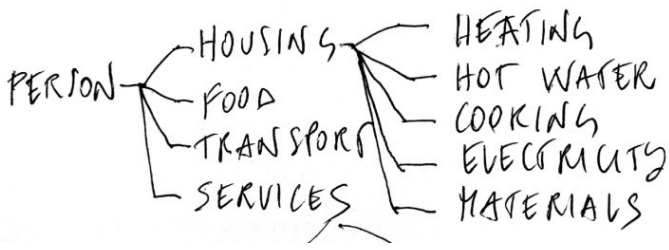

Figure 2. Branched scheme of the items that make up the environmental loads of the home in a broader set that constitutes the consumption categories of a person's lifestyle

The georeferenced transposition of these dynamics would involve a polar branched visualization that makes the relationships between the main energy and material flows and the territory easily understandable. The same territory can be made up of areas of different extensions characterized by properties useful for the analysis and verification of the effectiveness of possible improvement actions.

The simplified map in figure 3 distinguishes the territorial area into three domains:

- The private area, defined by the plot or area on which an individual's home or private appurtenances fall. 
- The local area (an arbitrary definition that can include areas of different extension depending on the survey)

- $\quad$ The global one.

In particular, the local and global territorial areas will be used to investigate how possible good practices can be described in a map to represent useful information to test the principles of a generative economy process.

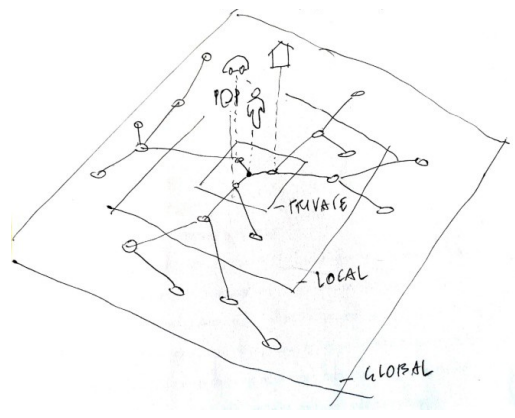

Figure 3. Simplified Impact Geography of the consumption categories in figure 2 , in the IG the territory is made up of different areas, private, local and global.

\section{PRELIMINARY TOOLKIT APPLICATIONS}

\subsection{Mapping the GE principles}

The transposition of good practice features into georeferenced maps is carried out firstly by building specific Impacts Geographies (IG) and Resource Geographies (RG) associated with the activities that characterize it, and secondly by testing the potential for use of the IGs and RGs in verifying compliance with the 7 principles of GE processes.

The RG and IG tools are an integral part of the GED Toolkit and are applied to real case studies with the aim of understanding which data and indicators can implement these tools to orient design choices towards compliance with GE principles.

Starting from the specific features of the good practices chosen, the functional units, the nodes and the main connections that characterize the internal processes of the good practice are briefly described in the following paragraphs. Each paragraph then briefly describes the GE principles of which the chosen practices are representative.

In the "Geographies" section, specific themes are therefore proposed to complement the information associated with local resources (RG), local demand and supply chain processes useful to satisfy this demand (IG). Finally, some preliminary proposals are made for indicators that can be calculated starting from the information mapped in the Geographies.

\subsection{Good Practice (GP1), investigating local biomass for winter heating potential}

This paragraph investigates the potential of georeferenced mapping of the workflows of a cooperative enterprise in a mountain area. The cooperative's activity is mainly oriented to the production of wood for winter heating of buildings.
3.2.1 Functional unit: A functional unit is here defined as a point of comparison useful to quantify and compare the indicators mapped with the purpose to define the greater or lesser effectiveness of proposed improvement scenarios. In this case, the supply chain is related to the production of energy for winter heating of homes. From the specific point of view of the LCA, the efficiency of this process must be assessed starting from an adequate functional unit: in this case, the energy needed to keep a person in comfort during the winter season.

3.2.2 Nodes and connections: The development of improvement scenarios can act on the various nodes that make up the production and consumption chains and on their connections. They can be taken as an example of the main supply chain nodes: the production of fuel, transformations, heat production and the final use of heat (identifiable in the following images by a numerical sequence). As far as the connections between the nodes are concerned, the main variables regard the distance and the means of transport (identifiable in the following images by the letter T)

In this specific case, the main energy source is forest wood, and the main nodes and connections of the supply chain are:

1. Timber cutting.

T1. Logs transport.

2. Transformation into wood chips.

3. Wood chips drying.

T2. Wood chips transport.

4. Combustion in the heating system.

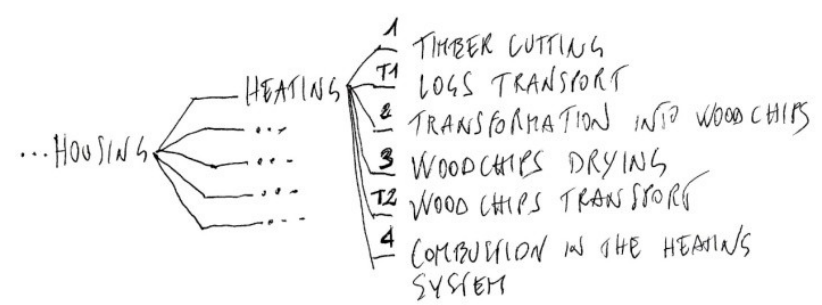

Figure 4. Branched scheme of the different nodes of GP1

Starting from this level of resolution typical of a simplified LCA, we intend to investigate the advantages of transposing the data associated with the supply chain nodes into IG and RG to support the development of improvement scenarios.

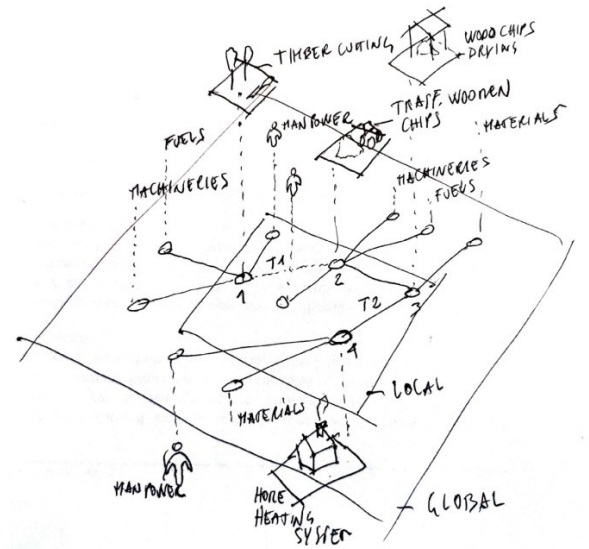

Figure 5. Supply chain simplified Impact Geography of local wooden biomass for winter heating. 
3.2.3 Principle 6: In the specific case related to verifying compliance with the principle of sustainability, the territorial database should include the following themes to be associated with the macro-groups of the RG and IG :

\section{Geographies}

RG1: Mapping of areas intended for wood sourcing, divided by category, associated with the yield value in terms of energy production and $\mathrm{CO}_{2}$ absorption (Fig.6)

IG1: mapping of fuel consumption by census section (Fig.6)

IG2: mapping of supply chain processes (Fig.6)

(RG1, IG1): The superimposition of RG1 and IG1 makes it possible to bring together local demand and supply, verifying the principles linked to P6. In order to verify the sustainability of the proposed chain, the withdrawal and emissions flows associated with the activity must be compatible with the regenerative cycles of the forest. The quantitative data mapped in RG1, together with data in IG1, allow assessing the extension of the productive land useful to ensure that the local energy demand coincides with, or is less than, the ecosystem's capacity to produce this resource.

(IG1, IG2): The association of IG1 and IG2 makes it possible to understand which quantities are associated with all the main steps in the supply chain and therefore to understand the amount of energy required, the costs and the workforce associated with each step. If IG1 allows quantifying the energy associated with the local demand for heating, IG2 provides the quantities of energy and matter needed for each step of the supply chain and locates the input and output flows. In the event that this information is superimposable with other RG and IG, integration of IG2 would allow further refinements to adopt some more precise design strategies, aimed at increasing the level of sustainability of the process.

-For example using locally available renewable sources to power supply chain processes would be made possible by mapping other renewable sources such as solar energy to produce electricity and heat or energy from agricultural production:

RG2: electricity from the sun.

RG3: heat from the sun.

RG4: energy from agricultural production: fuel oil.

\section{Indicators}

- The ratio between the amount of renewable energy used in the process and the total energy used.

- The average value of the ratios between the regeneration speed of renewable material resources used in each node compared to the withdrawal speed (greater than zero).

Principle 3a: The georeferencing of the supply chain nodes makes it possible to carry out assessments on the involvement of the local context in the processes (compliance with the Principle of place).

\section{Geographies}

RG1 (see paragraph 3,2,3)

\section{Indicators}

- Quantity of local material used in the process, compared to the total material used in the process (expressed in $\mathrm{kg}$ )

- Amount of local renewable energy used in the process compared to the total energy needed.

- Amount of local labour usable out of the total labour used in the process.

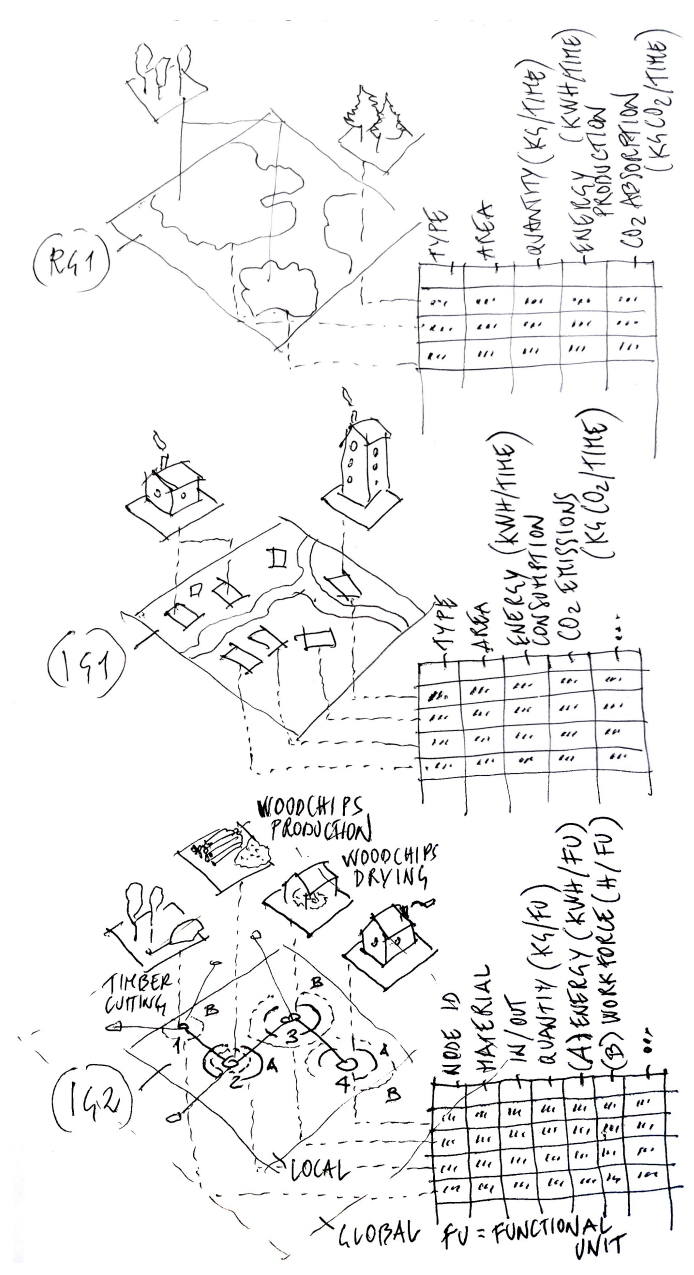

Figure 6. Some of the Geographies presented in order to verify compliance with the Principle of sustainability (P6)

3.2.4 Principle 1: The principle of community and inclusion could be mapped in a rough and simplified way by enriching the information associated with IGs (IG1, IG2, ...) with numerical values regarding the necessary workforce (hours of manpower).

\section{Geographies}

RG5/7: In regards to P1, the same Resources Geographies could include themes related to the available workforce (RG5, number of resident students, RG6 number of resident unemployed, RG7 number of pensioners) (for the Italian context these values can be mapped to the resolution of the census section. Data are available from ISTAT, the Italian National Institute of Statistics (www.istat.it).

\section{Indicators}

- The number of local operators involved in the process, compared to the inhabitants offering labour, (the residents can be mapped in the RG5-7 while those employed in the IG2 supply chains). 
3.2.5 Principle 2: As regards P2, the labour force indicator should in this case be better described, associating the total number of hours required for each node in the supply chain with the level of specialization/training necessary to provide such labour.

\section{Geographies}

RG8: The verification of social inclusion should include specific fields relating to residents offering work by distinguishing the fragile categories from the rest of the resident population.

\section{Indicators}

- The amount of unskilled labour that insists in the local area could be an indicator of possible potential social inclusion.

- The number of man-hours that can be activated within the territorial area defined as local.

- The number of inhabitants belonging to fragile categories involved in the process (IG2) compared to the total of those present in the local area (RG8).

\subsection{Good Practice (GP2), alternative currency to boost local tourism}

The case study activities refer to a community cooperative in Biccari, in the province of Foggia, Italy. In particular, the cooperative, to encourage tourism activities in its territorial area, makes available cumulative and exchangeable discount vouchers under the form of alternative local currency (https://www.coopbiccari.it/). The strategy adopted in this case is the use of a currency that is valid only within a predefined territory. The greater the possibility of locally closing the cycles that feed the main categories of consumption of the tourist, the longer will be the timespan for which the Bic will circulate before being exchanged back into conventional currency.

3.3.1 Functional unit: In order to understand how much it is possible to locally maintain the economic flows activated by tourists, specific IGs associated with functional units such as 1 meal, $1 \mathrm{~km}$ route, 1 bed, have been developed.

The typical day of the tourist, which constitutes the main functional unit useful for the formulation of improvement project scenarios, is, in turn, made up of basic elements such as the meal, the $\mathrm{km}$ travelled and the beds, intended as the amount of sleeping places.

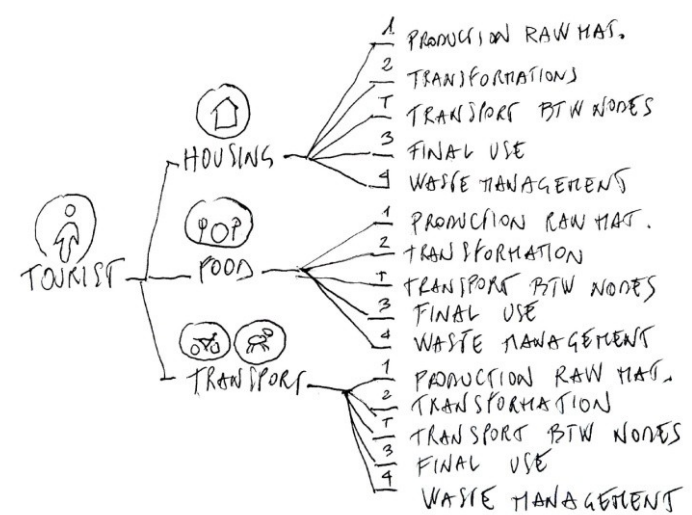

Figure 7. Branched scheme of the main flows associated with a tourist typical day.

\subsubsection{Nodes and connections:}

1. Place of production of the raw materials used in a typical day of the tourist (eating, sleeping, moving)

T. Transport to the main transformation nodes.

2. Activities useful for transformation.

3. Place of the final use of the product and service.

4. Management of waste and scraps.

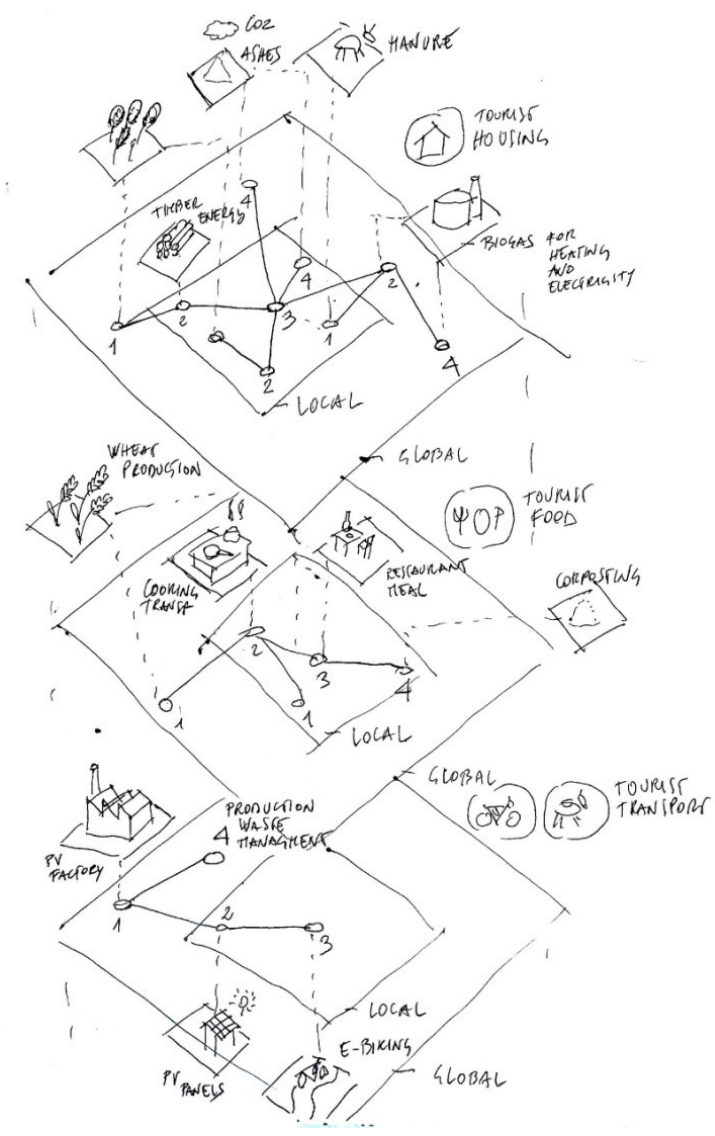

Figure 8. Simplified Impact Geography of the main tourist facilities.

Principle 3b: in this specific case project scenarios inherent to these strategies should be able to map:

\section{Geographies}

RG9: Tourist willingness to pay. By associating the number of beds available with the ability to spend associated with food, transport and residence.

\section{Indicators}

- The number of active cycles in the supply chain associated with the functional units, which close completely in the local context.

- The amount of money that affects cycles that close locally compared to the total spent in the unit of time by the tourist (for example daily).

\subsection{Good Practice (GP3), cooperative that deals with} the self-construction of solar thermal panels

In this case, the IGs - RGs were applied to the mapping of the activities of a cooperative that deals with the self-construction of solar thermal panels. 
3.4.1 Functional unit: In this case the functional unit is the unit of energy produced by the solar panel.

3.4.2 Nodes and connections: In this specific case, in order to produce $1 \mathrm{kWh}$ of energy for domestic hot water, the following are necessary:

1. A defined amount of solar energy, depending on the efficiency of the installation.

2. The different processes useful for the production of the solar panel are divided by main material (wooden elements, insulating material, copper elements, glass elements, etc.).

3. The different processes useful for the maintenance of the solar panel.

3.4.3 Principle 4: This practice can be used to better illustrate how IG and RG can be useful to pursue the Principle of good work.

Geographies

RG5/7 (see paragraph 3,2,5)

Indicators

- The georeferencing of the supply chain nodes could make it possible to privilege among the improvement choices those that maximize local work at the same total cost per unit of renewable energy produced. For this to be possible, each node has to contain information on the costs incurred for the material sourcing, the costs for the purchase of machinery, to be compared with the costs of local manpower.

3.5 Good Practice (GP4), cooperative for the selfproduction of electricity from renewable sources

In the specific case of the community cooperative of Melpignano, in the province of Lecce, the roofs of public and private properties are involved for the installation of photovoltaic systems with the aim of self-producing electricity

3.5.1 Functional unit: The functional unit of reference, in this case, is the surface area of installed photovoltaic panels.

\subsubsection{Nodes and connections:}

1. The total amount of energy and materials used for the construction of the photovoltaic panels.

T1. The transport of such materials.

2. The installation of the solar panel system.

3. System maintenance.

$4+$ T2. Decommissioning of the solar energy system.

3.5.3 Principle 5: The principle of democratized ownership: From the analysis of the activities of some community cooperatives emerges that the triggering of generative economic processes arises from the provision of renewable local resources incident on publicly owned territories, for example, abandoned agricultural land, roofs for the production of solar energies, management of public forest assets. The mapping through GIS of available and unused public resources is a good indicator to verify the transferability of good practices.

\section{Geographies}

RG10: Type and amount (square meters) of property involved, whether public or private.
RG11: The number and amount of involved properties belonging to the workers.

\section{Indicators}

- The percentage of public ownership out of total ownership in economic value.

- Th percentage of ownership belonging to internal workers.

- The number of owners resident locally out of total owners.

3.5.4 Principle 7: The principle of ethical finance: One of the resources that a territorial information system can make available to trigger ethical finance processes is the mapping of the expenditure flows of an established community, referring in particular to food, housing and mobility. This georeferenced information gives the possibility to understand the possible minimum local financial flows useful for redirecting the consumption flows of the community towards local processes of generative economy.

\section{Geographies}

RG12: expenses associated with the main consumption categories and mapped by census section.

\section{Indicators}

- Public expenses present on the territory

- Private expenses present on the territory

\section{REFERENCES}

Baccini, P., Brunner, P. H., 2012: Metabolism of the Anthroposphere, Second Edition, MIT Press, Cambridge.

Clementi, M., Fontana, C., Rogora A., 2018: Open Network for local self sustainability, boosting bioregional development through an open data sharing system. Int. Arch. Photogramm. Remote Sens. Spatial Inf. Sci., XLII-4/W8, 27-33. https://doi.org/10.5194/isprs-archives-XLII-4-W8-27-2018.

Daly, H.E., 1990 : Toward some operational principles of sustainable development, Ecological Economics, 2, 1- 6.

Daly, H. E., Farley, J., 2004: Ecological Economics. Principles and Applications. Island Press, Washington DC.

Kelly, M., 2012: Owning Our Future. Berrett-Koehler Publishers, San Francisco.

Kelly, M., Howard, T., 2019: The Making of a Democratic Economy. Berrett-Koehler Publishers, San Francisco.

Loiseau, E., Aissani, L., Le Feon, E., Laurent, F., Cerceau, J., Sala, S., Roux, P., 2018: Territorial Life Cycle Assessment (LCA): What exactly is it about? A proposal towards using a common terminology and a research agenda. Journal of Cleaner Production, 176, 474-485.

https://doi.org/10.1016/j.jclepro.2017.12.169.

Odum, H. T., 1996: Environmental Accounting, Emergy and Environmental Decision Making, John Wiley \& Sons.

Rodríguez, C., Ciroth, A., Srocka, M., 2014: The importance of regionalized LCIA in agricultural LCA - new software implementation and case study. LCA Food Conference 2014 (LCA Foods 2014) in San Francisco, USA, 8-10 October 2014. 